\title{
Statistical characterization of extreme hydrologic parameters for the peripheral river system of Dhaka city
}

\author{
Sarfaraz Alam*, Muhammad Sabbir Mostafa Khan \\ Department of Water Resources Engineering, Bangladesh University of Engineering and Technology, Dhaka 1000, Bangladesh
}

Email address:

sarfaraz@wre.buet.ac.bd (S. Alam),mostafakhan@wre.buet.ac.bd (M. S. M. Khan)

To cite this article:

Sarfaraz Alam, Muhammad Sabbir Mostafa Khan. Statistical Characterization of Extreme Hydrologic Parameters for the Peripheral River System of Dhaka City. Journal of Water Resources and Ocean Science. Vol. 3, No. 3, 2014, pp. 30-37. doi: 10.11648/j.wros.20140303.11

\begin{abstract}
Selection of appropriate probability distribution function is one of the most important steps of frequency analysis. Due to the existence of large number of distributions, hydrologists follow different methods to select the best one. In this paper, annual maximum, minimum water level and discharge of five peripheral rivers, namely Buriganga, Turag, Tongi, Balu and Lakhya around Dhaka city have been analyzed to compute the basic statistics and fit them with sixty two probability density functions (PDF). Three goodness-of-fit (GoF) statistics, namely Chi-square, Kolmogorov-Smirnov and Anderson Darling were used to rank each of the distribution. Furthermore, ranks obtained from three GoF were used to compute overall rank of all distributions for each hydrologic parameter. The study reveals that, four different distributions were found best fit for four extreme cases. Dagum (4P) and Chi-square (2P) fit best for annual maximum and minimum water level respectively, whereas Cauchy and Johnson SB were found for annual maximum and minimum discharge respectively. Moreover, ranks of frequently used distributions, namely General Extreme Value (GEV), Log-Pearson III (LP3), Log-normal (LN) and Gumbels were compared with the best fit distributions and did not give satisfactory results. The method used in this study would be helpful for flood frequency analysis of other rivers of Bangladesh. This may also be used for evaluation of best fit distribution of river system for other countries as well.
\end{abstract}

Keywords: Probability Distribution, Rank, Water Level, Discharge, Dhaka City

\section{Introduction}

Design of different types of hydraulic structures and flood plain zoning, economic evaluation of flood protection projects, etc. require information on flood magnitudes and their frequencies (Rakesh 2005). In addition low flow frequency analysis is also required for assessing water quality, water availability, navigability etc. Moreover climate change associated with global warming got potentiality to change the probability of these events. In particular, highly populated cities surrounded by rivers are vulnerable to flooding and pollution. Urban development and industrialization demand good estimation of both water level and discharge. Thus, it is necessary to explore the water level and discharge extremes around major cities, especially which are in highly populated regions dominated by socio-economic development and prone to pollution and flooding.

Reliable flood frequency distribution selection is one of the major problems faced by the hydrologists. This issue is very much important as different distributions may produce significantly different estimates for the same return period (Coulson 1991). In order to identify the appropriate probability distribution function a wide range of researches have been conducted previously (e.g., Cunanne 1973; Stedinger 1980; Stedinger et al.1992; Vogel RM 1993; Markiewicz et al. 2006; Mitosek et al. 2006; Laio F et al. 2009; Haddad K. 2010, Rahman A S. et al. 2013). Some of the commonly used distributions for annual maximum flood series include Extreme Value Type 1 (EV1), General Extreme Value (GEV), Extreme Value Type 2 (EV2), Two component Extreme Value, Normal, Log Normal (LN), Pearson Type 3 (P3), Log Pearson Type 3 (LP3), Gamma, Exponential, Weibull, Generalised Pareto and Wakeby (Cunnane 1989; Bobee et al.1993). Furthermore, there is no theoretical basis for the use of a single distribution over others, especially when analyzing a relatively short annual flood series for predicting the magnitude of extreme events (Gumbel 1958). Goodness of fit test is often used to select appropriate probability distribution for frequency analysis. Discrepancies may also arise from the use of different 
parameter estimation methods, such as method of moments, maximum likelihood and probability-weighted-moments (Betül Saf 2009). Different goodness-of- fit statistics, such as Chi-square, Kolmogorov-Smirnov and Anderson Darling may also show different ranks for each type of distribution.

A number of studies have been conducted on the rivers of Bangladesh using frequently used distribution functions. Ferdows M (2005) compared three frequently used distributions, namely Log Normal (Two parameters, LN2 and three parameters, LN3); Extreme value Type-1 (EVl) or Grumbel and Log-person type-3 (LP3), using annual peak flow of three major rivers (Meghna, Brahmaputra, Ganges-5 stations). In Bangladesh, four distributions are mainly used for at-sit frequency analysis of annual maximum discharge. Gumbel and LN distribution are used by Bangladesh Water Development Board and few departments/ firms respectively, whereas LP3 and GEV were used in National Water Plan and Flood Action Plan respectively (Karim MA and Chowdhury JA. 1995). Karim MA and Chowdhury JA. (1995) suggested the use of GEV for flood frequency analysis of the rivers of Bangladesh. Bari MF. et al.(2002) found that LP3 is more suitable for low flow frequency analysis for the rivers in North-West Bangladesh. So, almost all the researches on low and high flow were conducted using frequently used distributions.

In this study an attempt has been made to identify the best distributions for annual maximum, minimum water level and discharge. The study area is located at one of the most densely populated region in the world. Dhaka, the capital city of Bangladesh is surrounded by a number of rivers, namely Buriganga, Turag, Balu, Lakhya and Tongi. Annual maximum, minimum water level and discharge data of these rivers were used to compute the basic statistics and fit them with sixty two distributions. Three goodness-of-fit (GoF) statistics, namely Chi-square, Kolmogorov-Smirnov and Anderson Darling were used to rank each distribution. Furthermore, median of the ranks obtained from three GoF for each distribution were used to compute overall rank of all PDFs for each extreme hydrologic parameter, likewise Table 5 shows the ranks for annual maximum water level . Top three distributions for each station and each type of dataset were finally computed. Ranks of frequently used distributions, namely GEV, LP3, LN and Gumbels are also shown to assess their performance for different hydrologic extreme cases.

\section{Study Region and Data}

\subsection{Study Region}

Dhaka city is highly populated and influenced by the rapid socio-economic growth. The area of the city is 360 $\mathrm{km} 2$ with an estimated growth rate of $4.2 \%$ per annum that labeled the city as a mega city (Haigh, 2004; Karn and Harada, 2001; Rahman S. and Hossain, F., 2007). Elevation above MSL is $4 \mathrm{~m}$. Buriganga, Turag, Balu, Tongi and Lakhya are the peripheral river system around Dhaka city as shown in Fig 1. The area is greatly affected by the monsoon rainfall leading to flood and water logging. Considerable attention has been paid to understand the occurrence of flood of different return period.

\subsection{Data Collection}

Yearly maximum, minimum water level for 6 stations and discharge for 3 stations were collected from Bangladesh Water Development Board (BWDB). Location of the gauging stations can be referred to Fig 1. Detailed information of the dataset is given in Table 1. Other than one station on Turag river all the stations are subjected to tidal flow.

\section{Methodology}

In this research sixty one probability distribution functions (PDF) were used to fit the observed water level and discharge dataset. The list of PDF's used are given in Table 2.

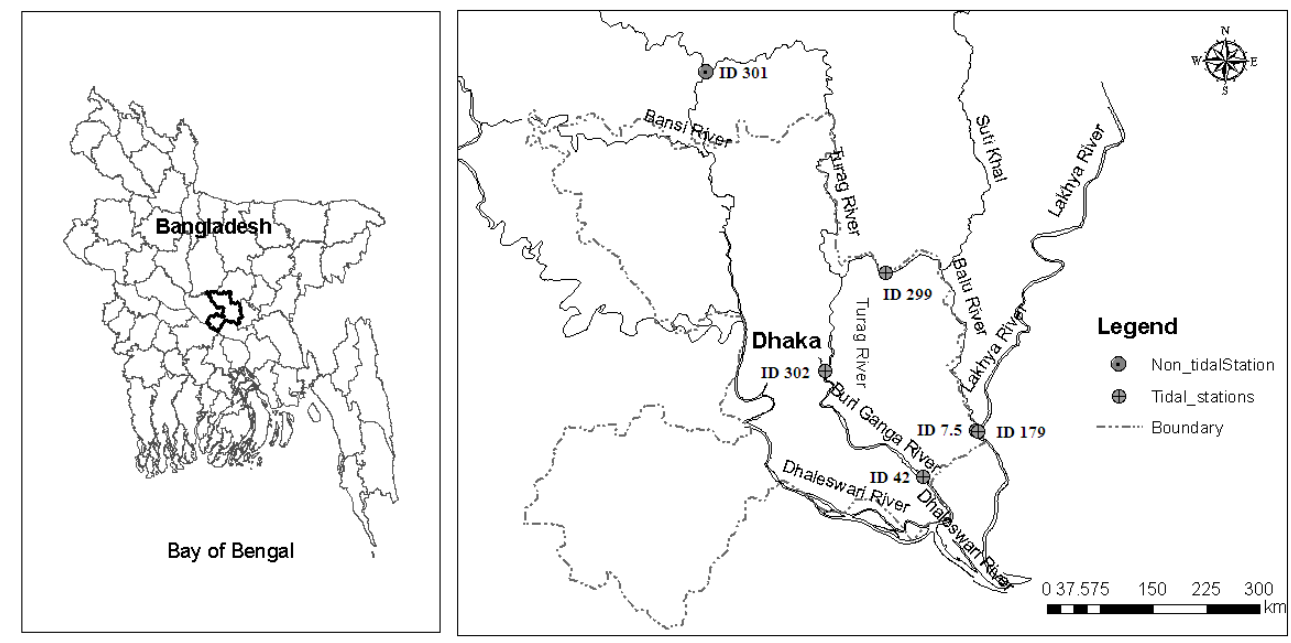

Figure 1. (a) Bangladesh map (b) Peripheral river system of Dhaka city (right). 
Table 1. Dataset of water level and discharge station location

\begin{tabular}{llllll}
\hline Station id & Station & Longitude & Latitude & River & Type \\
\hline 301 & Kaloikor & 90.210 & 24.082 & Turag & Non Tidal WL \& Q \\
42 & Dhaka (Mill Barak) & 90.445 & 23.677 & Buriganga & Tidal WL \\
302 & Mirpur & 90.338 & 23.783 & Turag & Tidal WL \\
299 & Tongi Khal & 90.404 & 23.882 & Tongi & Tidal WL \\
179 & Demra & 90.505 & 23.723 & Lakhya & Tidal WL \& Q \\
7.5 & Demra & 90.502 & 23.723 & Balu & Tidal WL \& Q \\
\hline
\end{tabular}

Table 2. Probability density functions used for fitting all hydrological dataset.

\begin{tabular}{|c|c|c|c|c|c|c|c|}
\hline Beta & Burr & Burr (4P) & Cauchy & Chi-Squared & Chi-Squared (2P) & Dagum & Dagum (4P) \\
\hline Erlang & Erlang (3P), & Error & Error Function & Exponential & Exponential (2P), & Fatigue Life & $\begin{array}{l}\text { Fatigue Life } \\
(3 \mathrm{P})\end{array}$ \\
\hline Frechet & Frechet (3P) & Gamma & Gamma (3P) & $\begin{array}{l}\text { Gen. Extreme } \\
\text { Value }\end{array}$ & Gen. Gamma & $\begin{array}{l}\text { Gen. Gamma } \\
\text { (4P) }\end{array}$ & Gen. Pareto \\
\hline $\begin{array}{l}\text { Gumbel } \\
\text { Max }\end{array}$ & Gumbel Min & Hypersecant & Inv. Gaussian & $\begin{array}{l}\text { Inv. Gaussian } \\
\text { (3P) }\end{array}$ & Johnson SB & Kumaraswamy & Laplace \\
\hline Lognormal & Lognormal (3P) & Nakagami & Normal & Pareto & Pareto 2 & Pearson 5 & $\begin{array}{l}\text { Pearson } 5 \\
(3 \mathrm{P})\end{array}$ \\
\hline Pearson 6 & Pearson6 (4P) & Pert & Power Function & Rayleigh & Rayleigh (2P) & Reciprocal & Rice \\
\hline Student's t & Triangular & Uniform & Weibull & Weibull(3P) & Johnson SU & Levy & $\operatorname{Levy}(2 P)$ \\
\hline Log-Gamma & Log-Logistic & Log-Logistic(3P) & Log-Pearson 3 & Log-Normal & & & \\
\hline
\end{tabular}

For each station annual maximum, minimum water level and discharge were plotted using all the distributions above (few were found not applicable in some cases). Goodness of fit was performed using Chi-Square, Kolmogorov-Smirnov and Anderson Darling. Ranks according to these three goodness of fit showed a great variation. Median of the ranks obtained from goodness of fit for each PDF was used to rank all the PDFs. A sample example is given in Table 3 showing ranks of maximum water level of Turag river at station 301. PDF's such as General Extreme Value (GEV), Log Pearson Type III, Log Normal and Gumbels which are mostly used for extreme value analysis are shown in Table 3 to highlight their ranking. All the distributions were fitted and ranked using the tool Easyfit. Three goodness of fit method gave separate ranking for each PDF. Median of the ranks obtained from three GoF for each distribution was used to compute the overall rank of all the PDFs. This procedure was followed for maximum, minimum water level and discharge for each station. Finally all these ranks were used to obtain the best fit distributions for each extreme hydrologic parameter. A sample example for station 301 (Turag) is shown in Table 9 (Appendix) which illustrates the best fit distributions obtained following the above procedure. Best fit distributions found from different GoF statistic and median of the ranks for station 301 are shown in Fig 2.

\section{Results and Discussion}

\subsection{Basic Statistics}

In order to understand the statistical properties of annual maximum and minimum water level and discharge of the peripheral rivers of Dhaka city, basic statistics have been computed (Table 3-4). We have described descriptive statistics such as max, min, range, min, variance, standard deviation, coefficient of variation, standard error, skewness and excess kurtosis. Considering annual maximum water level (Table 3), station 301 (Turag) gave both highest and lowest WL values of 10.48 and $2.27 \mathrm{mPWD}$ respectively with highest mean of $7.7 \mathrm{mPWD}$. Maximum and minimum range of 8.21 and $2.55 \mathrm{mPWD}$ were found at station 301 and 179 (Lakhya) respectively. Standard deviation and coefficient of variance were also highest at station 301 with values 1.78 and 0.23 respectively, whereas minimum values were 0.5 and 0.09 respectively at station 179 . Other than station 179 all the stations showed negative skewness. In context of excess kutosis station 299(Tongi) gave highest value of 4.01 and the lowest value 0.69 was found at station 179. Similarly considering annual minimum water level, station 301(Turag) is having highest range $2.42 \mathrm{mPWD}$ (2.91-0.49) and standard deviation 0.56. Whereas station 301 (Lakhya) was found to have lowest range $0.94 \mathrm{mPWD}$ and st. deviation 0.16. Highest and lowest coefficient of variation were found 0.34 and 0.18 at station 301 and 7.5 (Balu) respectively. Stations other than station 301 and 7.5 possess positive skewness. With regard to excess kurtosis station 301 has a negative value of -0.76 , whereas maximum value of 3.64 is associated at station 302 (Turag).

Moreover considering annual maximum discharge of all three stations (Table 4), station 179 gives the highest and mean discharge $2610 \mathrm{~m} 3 / \mathrm{s}$ and $1947.3 \mathrm{~m} 3 / \mathrm{s}$ respectively with minimum standard deviation, coefficient of variance and skewness of 378.44, 0.19 and -1.35 respectively. Maximum standard deviation and coefficient of variation were found 462.94 and 0.91 at station 301 and 7.5 respectively. Excess kurtosis of 13.53 at station 7.5 was quite higher than the minimum value 2.58 found at station 301. Similarly considering annual minimum discharge of all the stations, station 179 gives highest mean and standard deviation of $647.24 \mathrm{~m} 3 / \mathrm{s}$ and 316.94 with negative skewness and kutosis of -0.02 and -0.81 respectively. 
Whereas lowest mean and standard deviation were computed at station 301, though it possess highest coefficient of variation of 1.04 and excess kurtosis 14.77. Considering all discharge dataset it was found that discharge variation is highest at station 301 (2200-0.42 $\mathrm{m} 3 / \mathrm{s}$ ), standard deviation also varied greatly (462.94 to 3.26) at this station. Station 179 has a tendency to show negative skewness which is opposite to others. So, considering all the annual water level dataset highest variation (10.48-0.49) and standard deviation $(1.78,0.56)$ are associated with station 301 which is non tidal in behavior. Most of the stations showed negative skewness while annual maximum WL considered, whereas the scenario was vice versa considering annual minimum WL. Other than one case (Annual minimum WL, station $301=$ -0.76) all the stations showed positive excess kurtosis.

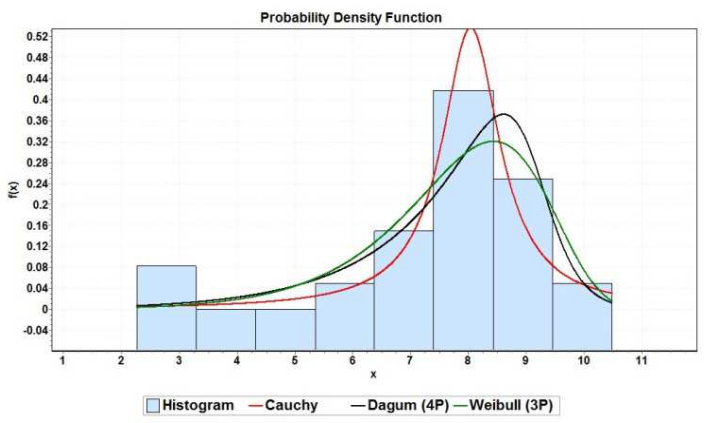

a)

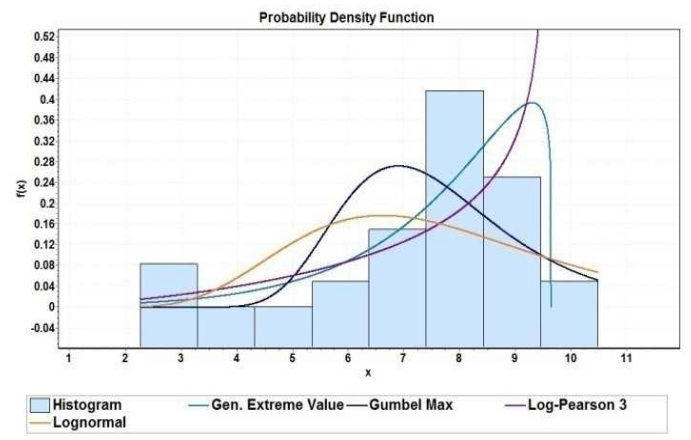

b)

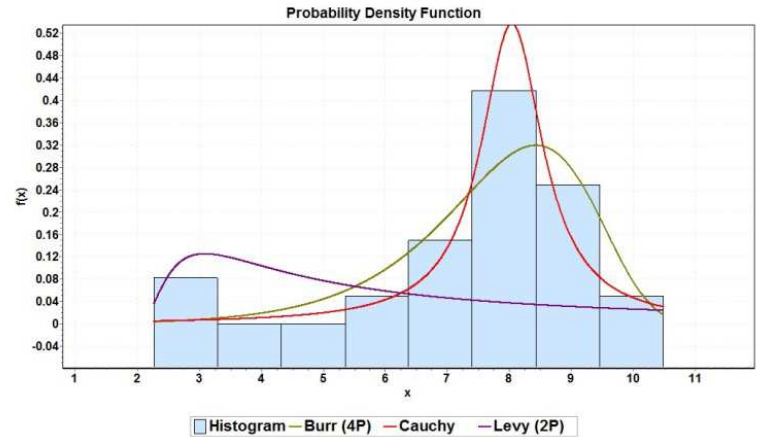

c)

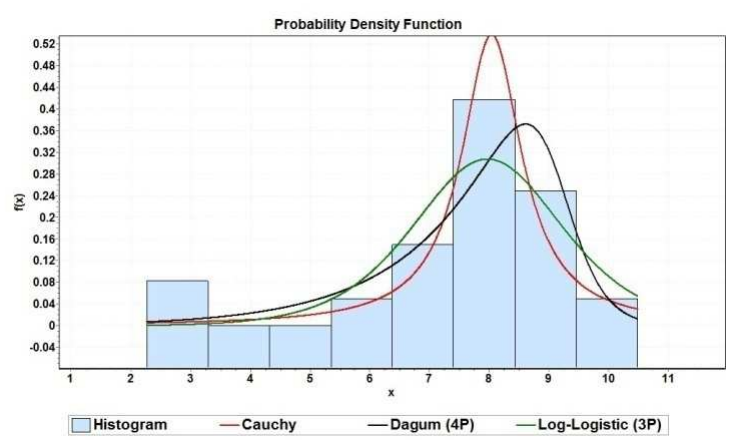

d)

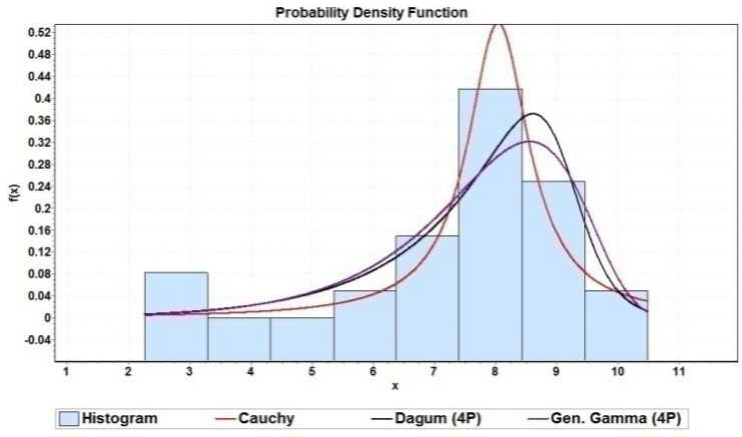

e)

Figure 2. Probability density function plotting of station 301 for annual maximum WL a) Best 3 based on the median of ranks obtained from Goodness-of-fits b) Frequently used distributions c) Best 3 according to Kolmogorov Smirnov d) Best 3 according to Anderson Darling e) Best 3 according to Chi-Squared

Table 3. Descriptive statistics of annual water level ( $m P W D)$ for individual stations

\begin{tabular}{|c|c|c|c|c|c|c|c|c|c|c|c|c|}
\hline Station Id & River & Max & Min & $\mathbf{N}$ & Range & Mean & Variance & Std. Dev & Coeff. of variation & Std. error & Skewness & Excess Kartosis \\
\hline \multicolumn{13}{|c|}{ Annual Max. Water Level (mPWD) } \\
\hline 301 & Turag & 10.48 & 2.27 & 60 & 8.21 & 7.7 & 3.18 & 1.78 & 0.23 & 0.23 & -1.8 & 3.38 \\
\hline 42 & Buriganga & 7.58 & 3.2 & 94 & 4.38 & 5.77 & 0.38 & 0.62 & 0.11 & 0.06 & -0.37 & 3.12 \\
\hline 302 & Turag & 8.35 & 2.71 & 54 & 5.64 & 6.18 & 0.9 & 0.95 & 0.15 & 0.13 & -0.63 & 2.57 \\
\hline 299 & Tongi & 7.84 & 2.71 & 49 & 5.13 & 5.99 & 0.88 & 0.94 & 0.16 & 0.13 & -1.34 & 4.01 \\
\hline 179 & Lakhya & 7.11 & 4.56 & 48 & 2.55 & 5.84 & 0.25 & 0.50 & 0.09 & 0.07 & 0.39 & 0.69 \\
\hline 7.5 & Balu & 7.09 & 2.57 & 46 & 4.52 & 5.82 & 0.47 & 0.69 & 0.12 & 0.10 & -2.19 & 10.47 \\
\hline \multicolumn{13}{|c|}{ Annual Min. Water Level (mPWD) } \\
\hline 301 & Turag & 2.91 & 0.49 & 60 & 2.42 & 1.66 & 0.31 & 0.56 & 0.34 & 0.07 & -0.17 & -0.76 \\
\hline 42 & Buriganga & 1.23 & 0.24 & 95 & 0.99 & 0.66 & 0.03 & 0.16 & 0.25 & 0.02 & 0.48 & 1.82 \\
\hline 302 & Turag & 1.71 & 0.12 & 56 & 1.59 & 0.80 & 0.06 & 0.24 & 0.29 & 0.03 & 0.64 & 3.64 \\
\hline 299 & Tongi & 1.52 & 0.53 & 50 & 0.99 & 0.94 & 0.04 & 0.20 & 0.21 & 0.03 & 0.86 & 1.15 \\
\hline 179 & Lakhya & 1.42 & 0.48 & 49 & 0.94 & 0.84 & 0.03 & 0.16 & 0.20 & 0.02 & 0.98 & 2.83 \\
\hline 7.5 & Balu & 1.4 & 0.34 & 48 & 1.06 & 0.93 & 0.03 & 0.17 & 0.18 & 0.02 & -0.29 & 2.96 \\
\hline
\end{tabular}


Table 4. Descriptive statistics of discharge $\left(\mathrm{m}^{3} / \mathrm{s}\right)$ for individual stations

\begin{tabular}{|c|c|c|c|c|c|c|c|c|c|c|c|c|}
\hline Station Id & River & $\operatorname{Max}$ & Min & $\mathbf{N}$ & Range & Mean & Variance & Std. Dev & $\begin{array}{l}\text { Coeff. of } \\
\text { variation }\end{array}$ & Std. error & Skewness & $\begin{array}{l}\text { Excess } \\
\text { Kartosis }\end{array}$ \\
\hline \multicolumn{13}{|c|}{ Annual Max. Discharge $\left(\mathrm{m}^{3} / \mathrm{s}\right)$} \\
\hline 301 & Turag & 2200 & 4 & 32 & 2196 & 686.11 & 214320 & 462.94 & 0.67 & 81.84 & 0.91 & 2.58 \\
\hline 179 & Lakhya & 2610 & 774 & 26 & 1935.8 & 1947.3 & 143210 & 378.44 & 0.19 & 74.22 & -1.35 & 4.3 \\
\hline 7.5 & Balu & 2077.3 & 140 & 21 & 1937.3 & 451.47 & 167850 & 409.69 & 0.91 & 89.4 & 3.52 & 13.53 \\
\hline \multicolumn{13}{|c|}{ Annual Min. Discharge $\left(\mathrm{m}^{3} / \mathrm{s}\right)$} \\
\hline 301 & Turag & 18.2 & 0.42 & 32 & 17.78 & 3.14 & 10.64 & 3.26 & 1.04 & 0.58 & 3.38 & 14.77 \\
\hline 179 & Lakhya & 1300 & 106 & 26 & 1194 & 647.24 & 100450 & 316.94 & 0.49 & 62.16 & -0.02 & -0.81 \\
\hline 7.5 & Balu & 288.52 & 16.1 & 21 & 272.42 & 73.33 & 4214.9 & 64.92 & 0.89 & 14.17 & 2.13 & 5.38 \\
\hline
\end{tabular}

Table 5. Best fit distributions and ranks of GEV, Log Pearson III, Log Normal and Gumbels for annual maximum water level.

\begin{tabular}{|c|c|c|c|c|c|c|c|}
\hline \multirow[t]{2}{*}{ St. id } & \multicolumn{3}{|c|}{ Best 3 distributions } & \multicolumn{4}{|c|}{ Ranks of mostly used PDF } \\
\hline & $\# 1$ & $\# 2$ & \#3 & GEV & Log Pearson III & Log Normal & Gumbels \\
\hline & \multicolumn{7}{|c|}{ Annual Max. water level } \\
\hline 301 & Cauchy & Dagum (4P) & Weibull (3P) & 25 & 31 & 41 & 34 \\
\hline 42 & Burr (4P) & Hypersecant & Dagum & 11 & 46 & 29 & 28 \\
\hline 302 & Hypersecant & Log-logistic & Laplace & 28 & 47 & 29 & 35 \\
\hline 299 & Log logistic (3P) & Laplace & $\operatorname{Dagum}(4 \mathrm{P})$ & 27 & 50 & 35 & 30 \\
\hline 179 & Dagum & Burr & Log-Logistic & 25 & 11 & 14 & 44 \\
\hline 7.5 & Cauchy & Dagum(4P) & Log logistic (3P) & 29 & 52 & 34 & 28 \\
\hline All & Dagum (4P) & Log-Logistic (3P) & Burr (4P) & 24 & 30 & 46 & 31 \\
\hline
\end{tabular}

Table 6. Best fit distributions and ranks of GEV, Log Pearson III, Log Normal and Gumbels for annual minimum water level.

\begin{tabular}{|c|c|c|c|c|c|c|c|}
\hline \multirow[t]{2}{*}{ St. id } & \multicolumn{3}{|c|}{ Best 3 distributions } & \multicolumn{4}{|c|}{ Ranks of mostly used PDF } \\
\hline & $\# 1$ & $\# 2$ & $\# 3$ & GEV & Log Pearson III & Log Normal & Gumbels \\
\hline & \multicolumn{7}{|c|}{ Annual Min. water level } \\
\hline 301 & $\operatorname{Dagum}(4 \mathrm{P})$ & Gen. Gamma & Error & 10 & 29 & 16 & 28 \\
\hline 42 & Laplace & Erlang & Hypersecant & 14 & 33 & 34 & 41 \\
\hline 302 & Dagum(4P) & Log-logistic & Burr & 8 & 7 & 14 & 34 \\
\hline 299 & Chi-squared & Burr (4P) & Chi-squared(2P) & 17 & 11 & 19 & 43 \\
\hline 179 & Cauchy & Chi-squared(2P) & Chi-squared & 24 & 21 & 17 & 44 \\
\hline 7.5 & Chi-squared(2P) & Log logistic (3P) & Logistics & 13 & 48 & 34 & 32 \\
\hline All & Chi-Squared (2P) & Burr (4P) & Chi-Squared & 10 & 28 & 16 & 42 \\
\hline
\end{tabular}

Table 7. Best fit distributions and ranks of GEV, Log Pearson III, Log Normal and Gumbels for annual maximum discharge.

\begin{tabular}{|c|c|c|c|c|c|c|c|}
\hline \multirow[t]{2}{*}{ St. id } & \multicolumn{3}{|c|}{ Best 3 distributions } & \multicolumn{4}{|c|}{ Ranks of mostly used PDF } \\
\hline & $\# 1$ & $\# 2$ & $\# 3$ & GEV & Log Pearson III & Log Normal & Gumbels \\
\hline & \multicolumn{7}{|c|}{ Max. Discharge } \\
\hline 301 & Error & Hypersecant & Laplace & 10 & 27 & 45 & 16 \\
\hline 179 & Cauchy & Log-logistic(3P) & Laplace & 20 & 40 & 23 & 29 \\
\hline 7.5 & Cauchy & Burr & Log-logistic(3P) & 19 & 31 & 12 & 19 \\
\hline All & Cauchy & Laplace & Log-Logistic (3P) & 17 & 36 & 25 & 18 \\
\hline
\end{tabular}

Table 8. Best fit distributions and ranks of GEV, Log Pearson III, Log Normal and Gumbels for annual minimum discharge.

\begin{tabular}{|c|c|c|c|c|c|c|c|}
\hline \multirow[t]{2}{*}{ St. id } & \multicolumn{3}{|c|}{ Best 3 distributions } & \multicolumn{4}{|c|}{ Ranks of mostly used PDF } \\
\hline & $\# 1$ & $\# 2$ & $\# 3$ & GEV & Log Pearson III & Log Normal & Gumbels \\
\hline & \multicolumn{7}{|c|}{ Min. Discharge } \\
\hline 301 & Fatigue Life & Logistic & Log Normal (3P) & 8 & 7 & 32 & 47 \\
\hline 179 & Dagum & Error & Johnson AB & 4 & 10 & 40 & 19 \\
\hline 7.5 & Gen. Pareto & Johnson AB & Fatigue Life (3P) & 4 & 12 & 2 & 52 \\
\hline All & Johnson SB & Gen. Extreme Value & Inv. Gaussian (3P) & 2 & 8 & 35 & 50 \\
\hline
\end{tabular}




\subsection{Ranking of Probability Distribution Function}

All the PDF were ranked for both water level and discharge at each station. Finally all those ranks were used to determine the ranking of PDF for similar type of dataset, such as max. wl, min. wl, max. Q and min. Q. Table 5-8 describes best three distributions for each type of dataset, ranks of mostly used distributions are also added in those tables.

Best fit distributions for annual maximum water level are listed in Table 5. It reveals great combination of various types of distributions. Considering all dataset Dagum(4P), Log-logistic(3P) and Burr (4P) were found the best three. On the other hand ranks of frequently used distributions GEV, LP3, LN and Gumbels were 24, 30, 46 and 31 respectively. Similarly, ranks of distributions for minimum WL are listed in Table 6. Frequently used distributions fell behind in this case too. The ranks obtained are 10, 28, 16 and 42 respectively. Whereas the best fit distributions are Chi-squared (2P), Burr (4P) and Chi-Squared.

Similar to water level, discharge dataset were also fitted to different distributions (Table 7-8). In case of annual maximum discharge various distributions were found best fit for different stations. Frequently used distributions didn't show good performance in this case. Ranks of frequently used distributions GEV, LP3, LN and Gumbels were 17, 36, 25 and 18 respectively. Best fit distributions were Cauchy, Laplace and Log-logistic (3P). Whereas, considering annual minimum discharge GEV (Generalized Extreme Value) gave a good result in combined ranking. But separately each station gave different best fit distributions. Best fit distributions for annual minimum water level were Johnson $\mathrm{SB}$, GEV and Inv. Gaussian (3P).

\section{Conclusion}

In this study annual maximum, minimum water level and discharge of the peripheral river system of Dhaka city have been analyzed to identify the best fit distribution among sixty two distributions. Three goodness-of-fit statistics (GoF), namely Chi-square, Kolmogorov-Smirnov and Anderson Darling were used to rank all distributions median of the ranks obtained from three GoF for each distribution were used to compute overall rank of all PDFs for each extreme hydrologic parameter. The study reveals that, four different distributions were found best fit for four extreme hydrologic cases. Dagum (4P) and Chi-square (2P) fit best for annual maximum and minimum water level respectively, whereas Cauchy and Johnson SB were found for annual maximum and minimum discharge respectively. The ranks of frequently used distributions GEV, LP3, LN and Gumbels were not satisfactory for almost all the hydrologic parameters.

\section{Recommendation}

The method used in this study would be helpful for flood frequency analysis of other rivers of Bangladesh. This may also be used for evaluation of best fit distribution for other countries as well.

\section{Acknowledgements}

Authors are gratefully acknowledging the cooperation rendered by Bangladesh Water Development Board (BWDB) for providing the necessary data.

\section{Appendix}

Table 9. Ranking of PDF for maximum water level of Turag river at Kaloikor station (st. id 301)

\begin{tabular}{|c|c|c|c|c|c|c|c|c|}
\hline \multirow[t]{2}{*}{ Distribution } & \multicolumn{2}{|c|}{$\begin{array}{c}\text { Kolmogorov Smirnov Ranking of PDF for maximum water } \\
\text { level of Turag river at Kaloikor station (st. id 301) }\end{array}$} & \multicolumn{2}{|c|}{ Anderson Darling } & \multicolumn{2}{|c|}{ Chi-Squared } & \multicolumn{2}{|c|}{ Median } \\
\hline & Statistic & Rank & Statistic & Rank & Statistic & Rank & Value & Rank \\
\hline Beta & 0.15 & 10 & 1.69 & 7 & 11.00 & 15 & 10 & 9 \\
\hline Burr & 0.16 & 12 & 2.78 & 13 & 11.09 & 16 & 13 & 13 \\
\hline Burr (4P) & 0.11 & 5 & 1.20 & 6 & 4.12 & 3 & 5 & 4 \\
\hline Cauchy & 0.09 & 1 & 0.61 & 1 & 0.79 & 1 & 1 & 1 \\
\hline Chi-Squared & 0.42 & 51 & 13.42 & 47 & 85.33 & 53 & 51 & 53 \\
\hline Chi-Squared (2P) & 0.37 & 50 & 10.98 & 43 & 70.84 & 51 & 50 & 51 \\
\hline Dagum & 0.16 & 11 & 1.87 & 9 & 13.21 & 19 & 11 & 10 \\
\hline Dagum (4P) & 0.10 & 3 & 0.97 & 2 & 10.52 & 14 & 3 & 2 \\
\hline Erlang & 0.29 & 42 & 8.43 & 37 & 23.58 & 37 & 37 & 36 \\
\hline Erlang (3P) & 0.22 & 28 & 4.39 & 21 & 16.77 & 31 & 28 & 27 \\
\hline Error & 0.19 & 18 & 2.73 & 12 & 8.36 & 10 & 12 & 12 \\
\hline Error Function & 0.92 & 59 & 554.77 & 60 & 932.97 & 54 & 59 & 59 \\
\hline Exponential & 0.47 & 53 & 17.66 & 51 & 22.18 & 34 & 51 & 53 \\
\hline Exponential (2P) & 0.43 & 52 & 14.76 & 49 & 8.86 & 12 & 49 & 49 \\
\hline
\end{tabular}




\begin{tabular}{|c|c|c|c|c|c|c|c|c|}
\hline \multirow[t]{2}{*}{ Distribution } & \multicolumn{2}{|c|}{$\begin{array}{l}\text { Kolmogorov Smirnov Ranking of PDF for maximum water } \\
\text { level of Turag river at Kaloikor station (st. id 301) }\end{array}$} & \multicolumn{2}{|c|}{ Anderson Darling } & \multicolumn{2}{|c|}{ Chi-Squared } & \multicolumn{2}{|c|}{ Median } \\
\hline & Statistic & Rank & Statistic & Rank & Statistic & Rank & Value & Rank \\
\hline Fatigue Life & 0.31 & 44 & 8.52 & 38 & 37.72 & 43 & 43 & 42 \\
\hline Fatigue Life (3P) & 0.21 & 25 & 3.96 & 19 & 16.46 & 26 & 25 & 22 \\
\hline Frechet & 0.37 & 49 & 12.13 & 45 & 67.57 & 50 & 49 & 49 \\
\hline Frechet (3P) & 0.28 & 40 & 7.57 & 34 & 25.91 & 38 & 38 & 38 \\
\hline Gamma & 0.23 & 30 & 6.18 & 29 & 13.27 & 20 & 29 & 28 \\
\hline Gamma (3P) & 0.21 & 26 & 4.40 & 22 & 17.30 & 32 & 26 & 24 \\
\hline Gen. Extreme Value & 0.13 & 8 & 12.53 & 46 & N/A & & 27 & 25 \\
\hline Gen. Gamma & 0.26 & 38 & 6.63 & 31 & 28.76 & 40 & 38 & 38 \\
\hline Gen. Gamma (4P) & 0.12 & 7 & 1.12 & 3 & 6.06 & 7 & 7 & 7 \\
\hline Gen. Pareto & 0.18 & 16 & 33.68 & 58 & $\mathrm{~N} / \mathrm{A}$ & & 37 & 36 \\
\hline Gumbel Max & 0.26 & 36 & 11.84 & 44 & 16.73 & 30 & 36 & 34 \\
\hline Gumbel Min & 0.14 & 9 & 1.71 & 8 & 8.17 & 8 & 8 & 8 \\
\hline Hypersecant & 0.18 & 15 & 2.91 & 14 & 11.65 & 17 & 15 & 15 \\
\hline Inv. Gaussian & 0.20 & 23 & 7.23 & 33 & 15.92 & 22 & 23 & 19 \\
\hline Inv. Gaussian (3P) & 0.20 & 22 & 3.88 & 17 & 16.45 & 25 & 22 & 18 \\
\hline Johnson SB & 0.18 & 14 & 19.27 & 53 & N/A & & 33.5 & 33 \\
\hline Kumaraswamy & 0.12 & 6 & 1.20 & 5 & 4.12 & 5 & 5 & 4 \\
\hline Laplace & 0.19 & 19 & 2.73 & 11 & 8.36 & 11 & 11 & 10 \\
\hline Levy & 0.58 & 57 & 22.39 & 55 & 36.62 & 42 & 55 & 57 \\
\hline Levy (2P) & 0.49 & 56 & 16.29 & 50 & 1.48 & 2 & 50 & 51 \\
\hline Log-Gamma & 0.31 & 45 & 9.64 & 40 & 38.01 & 44 & 44 & 45 \\
\hline Log-Logistic & 0.30 & 43 & 8.20 & 36 & 47.62 & 47 & 43 & 42 \\
\hline Log-Logistic (3P) & 0.10 & 2 & 1.97 & 10 & 5.54 & 6 & 6 & 6 \\
\hline Log-Pearson 3 & 0.18 & 17 & 14.32 & 48 & $\mathrm{~N} / \mathrm{A}$ & & 32.5 & 31 \\
\hline Logistic & 0.19 & 20 & 3.19 & 16 & 16.54 & 27 & 20 & 16 \\
\hline Lognormal & 0.29 & 41 & 7.86 & 35 & 35.34 & 41 & 41 & 41 \\
\hline Lognormal (3P) & 0.21 & 27 & 4.25 & 20 & 16.71 & 28 & 27 & 25 \\
\hline Nakagami & 0.17 & 13 & 5.07 & 26 & 10.46 & 13 & 13 & 13 \\
\hline Normal & 0.21 & 24 & 3.94 & 18 & 16.45 & 24 & 24 & 20 \\
\hline Pareto & 0.49 & 55 & 19.40 & 54 & 8.25 & 9 & 54 & 56 \\
\hline Pareto 2 & 0.48 & 54 & 18.33 & 52 & 22.45 & 35 & 52 & 55 \\
\hline Pearson 5 & 0.32 & 46 & 9.51 & 39 & 50.62 & 48 & 46 & 46 \\
\hline Pearson 5 (3P) & 0.24 & 33 & 5.02 & 25 & 14.06 & 21 & 25 & 22 \\
\hline Pearson 6 & 0.27 & 39 & 7.15 & 32 & 41.17 & 45 & 39 & 40 \\
\hline Pearson 6 (4P) & 0.25 & 34 & 5.25 & 28 & 20.05 & 33 & 33 & 32 \\
\hline Pert & 0.19 & 21 & 3.01 & 15 & 16.25 & 23 & 21 & 17 \\
\hline Power Function & 0.22 & 29 & 4.74 & 24 & 12.12 & 18 & 24 & 20 \\
\hline Rayleigh & 0.32 & 47 & 9.95 & 42 & 78.45 & 52 & 47 & 48 \\
\hline Rayleigh (2P) & 0.35 & 48 & 9.64 & 41 & 47.13 & 46 & 46 & 46 \\
\hline Reciprocal & 0.58 & 58 & 32.26 & 57 & 27.50 & 39 & 57 & 58 \\
\hline Rice & 0.25 & 35 & 5.15 & 27 & 16.73 & 29 & 29 & 28 \\
\hline Student's t & 0.92 & 60 & 208.24 & 59 & 1199.10 & 55 & 59 & 59 \\
\hline Triangular & 0.26 & 37 & 4.69 & 23 & 22.68 & 36 & 36 & 34 \\
\hline Uniform & 0.24 & 31 & 22.66 & 56 & N/A & & 43.5 & 44 \\
\hline Weibull & 0.24 & 32 & 6.53 & 30 & 55.19 & 49 & 32 & 30 \\
\hline Weibull (3P) & 0.11 & 4 & 1.19 & 4 & 4.12 & 4 & 4 & 3 \\
\hline Johnson SU & No fit & - & - & - & - & - & - & - \\
\hline
\end{tabular}




\section{References}

[1] Bari MF and Sadek S., Regionalization of low-flow frequency estimates for rivers in northwest Bangladesh, FRIEND 2002-Regional Hydrology: Bridging the Gap between Research and Practice (Proceedings of the fourth International FRIEND Conference held at Cape Town. South Africa. March 2002). IAHS Publ. no. 274.

[2] Betül Saf (2009), Regional Flood Frequency Analysis Using L-Moments for the West Mediterranean Region of Turkey, Water Resour Manage 23:531-551 DOI 10.1007/s11269-008-9287-z

[3] Bobee B, Cavidas G, Ashkar F, Bernier J, Rasmussen P (1993) Towards a systematic approach to comparing distributions used in flood frequency analysis. J Hydrol 142:121-136

[4] Coulson CH (1991) Manual of operational hydrology in B.C., 2nd edn. B.C. Water Management Division, Hydrology Section, Ministry of Environment, Lands and Parks, BC, Canada

[5] Cunanne C (1973) A particular comparison of annual maxima and partial duration series methods of flood frequency prediction. J Hydrol 18:257-271

[6] Cunnane C (1989) Statistical distributions for flood frequency analysis. WMO No. 718, WMP, Geneva

[7] Ferdows M and Hossain M (2005), Flood Frequency Analysis at Different Rivers in Bangladesh: A Comparison Study on Probabilitv Distribution Functions, Thammasat Int. J. Sc. Tech., Vol. 10, No. 3, 53-62

[8] Haddad K. and Rahman A. (2010). Selection of the best fit flood frequency distribution and parameter estimation procedure: a case study for Tasmania in Australia, Stoch Environ Res Risk Assess (2011) 25, DOI 10.1007/s00477-010-0412-1, 415-428

[9] Haigh M.J. (2004). Sustainable management of headwater resources: the Nairobi 'headwater' declaration (2002) and beyond. Asian Journal of Water, Environment and Pollution, Vol. 1, No. 1-2, 17-28.
[10] Karn S.K. and Harada, H. (2001). Surface water pollution in three urban territories of Nepal, India, and Bangladesh. Environmental Management, Vol. 28, No. 4, 483-496

[11] Karim MA and Chowdhury JA. (1995) A comparison of four distributions used in flood frequency analysis in Bangladesh, Hydrological Sciences Journal, 40:1, 55-66, DOI: $10.1080 / 02626669509491390$

[12] Laio F, Di Baldassarre G, Montanari A (2009) Model selection techniques for the frequency analysis of hydrological extremes. Water Resour Res 45:W07416. doi:10.1029/2007/WR006666

[13] Markiewicz I, Strupczewski WG, Kochanek K, Singh V (2006) Discussion of Non-stationary pooled flood frequency analysis. J Hydrol 276:210-223

[14] Mitosek HT, Strupczewski WG, Singh VP (2006) Three procedures for selection of annual flood peak distribution. J Hydrol 323: 57-73

[15] Rahman AS., Rahman A., Zaman MA., Haddad K., Ahsan A., Imteaz M. (2013), A study on selection of probability distributions for at-site flood frequency analysis in Australia, Nat Hazards (2013) 69:1803-1813 DOI 10.1007/s11069-013-0775-y

[16] Rahman S. and Hossain, F., (2007). Spatial Assessment of Water Quality in Peripheral Rivers of Dhaka City for Optimal Relocation of Water Intake Point. Water Resources Management, Vol. 1, No. 22, 377-391.

[17] Rakesh Kumar and Chandranath Chatterjee,(2005), Regional Flood Frequency Analysis Using L-Moments for North Brahmaputra Region of India, J. Hydrol. Eng, ASCE, Vol. 10, No. 1, 1-7, DOI:10.1061/(ASCE)1084-0699(2005)10:1(1)

[18] Stedinger JR (1980) Fitting lognormal distributions to hydrologic data. Water Resour Res 16(3):481-490

[19] Stedinger JR, Vogel RM, Foufoula-Georgiou E (1992) Frequency analysis of extreme events. In: Maidment DR (ed) Handbook of hydrology. McGraw-Hill, New York

[20] Vogel RM, McMahon TA, Chiew FHS (1993) Flood flow frequency model selection in Australia. J Hydrol 146(421):449 